\title{
Crítica do juízo teleológico e organismo em Kant e Schelling
}

\author{
Gabriel Almeida Assumpção \\ gabrielchou@gmail.com \\ Universidade Federal de Minas Gerais (UFMG), Belo Horizonte, MG
}

Resumo: A Crítica da faculdade de julgar (1790) foi recebida com entusiasmo pelos filósofos do idealismo alemão. No caso de Friedrich Schelling, as duas partes da obra foram influentes, de modo que não só a estética kantiana, mas também a teleologia foi marcante em sua trajetória filosófica. Observaremos como o filósofo de Leonberg acolhe, na Introdução às Ideias para uma filosofia da natureza (1797), a noção kantiana de organismo como dotado de autocausalidade, mas pensa-a nos quadros de uma filosofia pós-kantiana, buscando prescindir das noções de juízo reflexionante e também da ideia de "natureza como arte" (Natur als Kunst) para se pensar o organismo. Como Schelling vincula essa noção com a proposta de se pensar a unidade entre natureza e espírito a partir do próprio sujeito, e não de algo exterior a ele? Como Kant reagiria a tal proposta?

Palavras-chave: Finalidade; juízo reflexionante; Kant; natureza; organismo; Schelling.

\section{Critique of teleological judgment and organism according to Kant and Schelling}

Abstract: The Critique of Judgment (1790) was enthusiastically received by the German Idealists. In the case of Friedrich Schelling, both divisions of the work were influent, thus resulting that not only Kantian aesthetics, but also the teleology was a landmark in his philosophical itinerary. We attempt to observe how the philosopher of Leonberg receives, in the Introduction to the Ideas for a Philosophy of Nature (1797), the Kantian conception of organism as endowed with self-causality, but at the same time thinks it within the frame of a post-Kantian philosophy, leaving aside the reflective judgment and also the idea of nature as a product of art (Natur als Kunst) in order to think the organism. How does Schelling connect this notion with the proposal to think the unity between nature and spirit based on the own subject, and not on something external to it? How would Kant react to such a proposal?

Keywords: Kant; nature; organism; purposiveness; reflective judgment; Schelling.

\section{INTRODUÇÃO: “LER A 'CRÍTICA DA FACULDADE DE JULGAR TELEOLÓGICA' COM O ESPÍRITO”.}

Para Kant, há um desafio para o entendimento: a ideia de fim natural ou de organismo. É conhecida a afirmação segundo a qual não haveria um Newton capaz de explicar uma gramínea (KANT, 1968b, p. 
400) com base apenas no mecanismo ${ }^{1}$. O filósofo propõe, por analogia, um entendimento intuitivo que não leva em conta a combinação de partes, mas que intui o todo (KANT, 1968b, p. 407), prescindindo da discursividade do entendimento. Schelling se apropriou dessa proposição e pensa uma intuição intelectual (intellectuale Anschaung) que não se refere a objetos, mas que é um exercício da intuição de si como liberdade (SCHELLING, 1980, pp. 103-106). Para o filósofo, a autoconsciência não pode ser pensada por partes, mas apenas intuída de modo imediato. Com a intuição intelectual, o pensador alemão queria provar não apenas o eu, mas principalmente provar o eu Absoluto, para além da relação sujeitoobjeto, e instaurar a intuição intelectual como fundamento da filosofia da natureza e da filosofia da arte (PUENTE, 1997, p. 30-32).

No $₫$ XVI de Do eu como princípio da filosofia (1795) - um de seus primeiros escritos filosóficos Schelling recomenda a leitura da segunda parte da Crítica da faculdade de julgar (1790), designada "Kritik der teleologischen Urteilskraft" ("Crítica da faculdade de julgar teleológica”), com o espírito (Geist), como se deve fazer, aliás, com tudo que foi escrito por Kant, na opinião do filósofo de Leonberg (SCHELLING, 1980, p. 162). Ele menciona, nesse sentido - ainda que sem entrar em pormenores nessa obra- uma união do mecanismo com a teleologia, ainda que não determinável como objeto. A razão deve unificar mecanismo e teleologia, segundo um princípio superior que não seja determinável como objeto, que o autor chama, nesse momento inicial de sua trajetória filosófica (e servindo-se de terminologia fichteana), o Eu absoluto (SCHELLING, 1980, p. 174).

Em Kant, o conceito de finalidade da natureza em seus produtos é um conceito necessário para a faculdade de julgar humana, mas não determinante dos objetos. É um princípio subjetivo da razão para a faculdade de julgar, que possui um uso somente regulativo e, ao mesmo tempo, é tão necessariamente válido para nosso juízo como se fosse um princípio objetivo (KANT, 1968b, p. 404). Também para Schelling, somos compelidos a pensar de maneira finalista (isto é, a pensar as partes em função do todo), sendo que a finalidade do todo da natureza é algo que pensamos necessariamente, e não arbitrariamente. Nesse ponto, o filósofo de Leonberg aproxima-se da posição de Kant; a diferença é que este só aceita que pensemos a finalidade como máxima necessária subjetivamente, a partir da faculdade de julgar reflexionante, a qual aquele, por sua vez, designa como razão reflexionante (SCHELLING, 1994, p. 106).

A Crítica da faculdade de julgar, particularmente a "Crítica da faculdade de julgar teleológica", segunda parte da obra, é marcante no projeto schellinguiano de uma filosofia da natureza (DURNER, 1994, p. 34 ss) $)^{2}$, que deve ser compreendida, segundo Bicca, como uma radicalização ou um alargamento do ponto de partida de Kant e de Fichte, e não como retrocesso a uma metafísica dogmática (BICCA, 1989, p. 72). A concepção kantiana de organismo como autoprodução, que não pode ser apreciado adequadamente pelas categorias da mecânica, é algo muito influente na Introdução das Ideias para uma filosofia da natureza $(1797)^{3}$ e esse será o foco de nosso trabalho.

Ora, em 22 de janeiro de 1796, Schelling envia, de Stuttgart, uma carta a Niethammer, na qual fala de muitos planos em andamento, entre os quais um sistema de ética (que seria uma contraparte à Ética de Spinoza); uma filosofia da história da humanidade; e de "uma interpretação da Crítica da faculdade de julgar segundo meus princípios" ((...) eine Auslegung der Kritik der Urteilskraft nach meinen Principien $)^{4}$ (SCHELLING, 2001, p. 41). Essa interpretação não chegou a ver a luz do dia, pelo menos não foi exposta como tal em nenhuma obra especialmente dedicada ao tema. Uma hipótese de trabalho plausível seria 
considerar a Introdução às Ideias, de 1797, como uma interpretação schellinguiana peculiar da Terceira Crítica. Vejamos mais de perto os argumentos presentes na Terceira Crítica kantiana para, em seguida, examinarmos como a interpretação schellinguiana de 1797 ora se aproxima, ora se distancia do texto de Kant, dando ênfase à ideia de organismo e à recusa, da parte de Schelling, da noção kantiana de "natureza como arte" (Natur als Kunst) para se pensar a finalidade na natureza.

\section{ORGANISMO E JUÍZO REFLEXIONANTE EM KANT.}

O "Apêndice à Dialética Transcendental" da Crítica da razão pura (1781/1787) é particularmente esclarecedor em relação ao que mencionamos acima sobre a noção de princípio regulativo. É conhecido que, em Kant, há um emprego peculiar das ideais transcendentais no uso teórico da razão: elas nunca permitem um emprego constitutivo neste âmbito, uma vez que, se o fazem, elas são consideradas apenas conceitos dialéticos e pseudorracionais. O emprego regulativo, por outro lado, é excelente e necessário, direcionando o entendimento rumo a certo fim. É uma ideia, um "foco imaginário" do qual os conceitos do entendimento não procedem na realidade, mas ganham maior unidade e extensão. A unidade da razão sempre pressupõe a ideia "da forma de um todo de conhecimento que precede o conhecimento das partes e contém as condições para determinar a priori o lugar de cada parte e suas relações com as outras" (KANT, 1968a, p. B 672). A ideia da unidade do conhecimento e da própria natureza, para o pensador alemão, não se extraem diretamente da natureza: antes, somos nós que nos servimos de tais ideias para melhor e mais completamente interrogá-la (KANT, 1968a, p. B 673).

Não encontramos na natureza, por exemplo, a água pura, a terra pura, o ar puro. Exigimos, todavia, os conceitos dos mesmos em ordem a determinar adequadamente a parte de cada uma dessas causas naturais têm na produção dos fenômenos (KANT, 1968a, p. B 674). As ideias da razão não servem como princípios constitutivos para a extensão de nosso conhecimento teórico, mas como princípios reguladores da unidade sistemática do múltiplo do conhecimento empírico em geral, por meio do qual o conhecimento empírico é mais adequadamente assegurado dentro de seus próprios limites (KANT, 1968a, p. B 698-700).

Na Kritik der Urteilskraft, Kant se debruça, a partir do $\$ 64$, sobre o tema do organismo ou fim natural (Naturzweck). Trata-se de algo apenas possível como fim, ou seja, cuja origem não é causada pelo mecanismo da natureza, mas pela razão - portanto, de algo que só se deixa entender pela razão, e não pelo entendimento ou pela sensibilidade. A razão capta a necessidade de cada forma de um produto natural (KANT, 1968b, [\$ 64] p. 369s).

"Uma coisa existe como fim natural, se ela é causa e efeito de si mesma (ainda que em um duplo sentido)" (KANT, 1968b, [ $\$$ 64] p. 370). Ser causa e efeito de si mesmo ocorre das seguintes maneiras: (a) uma árvore gera outra: trata-se, nesse caso, da produção do mesmo gênero (Gattung). Algo se produz não individualmente, mas genericamente. Como efeito, a árvore é continuamente autoproduzida. Além disso, (b) uma árvore se produz como indivíduo (Individuum). Esse efeito é o crescimento, mas difere do crescimento segundo leis mecânicas. Trata-se, aqui, de uma espécie de geração (Zeugung). Há uma qualidade específico-peculiar (specifisch-eigenthümlicher Qualität) na árvore que o mecanismo natural externo a ela não consegue fornecer. Finalmente, (c) há uma relação de dependência recíproca entre as partes: cada parte da árvore produz-se a si mesma de forma tal que sua preservação depende 
reciprocamente da preservação das demais partes (cf. KANT, 1968b, [\$ 64] p. 371).

O conceito de uma coisa que seja fim natural não é constitutivo do entendimento ou da razão, mas pode servir como conceito regulador do juízo reflexivo, para guiar nossa investigação sobre tais objetos empregamos uma "analogia distante" (entfernten Analogie) com nossa própria causalidade de acordo com fins. "O conceito de uma coisa, como fim natural em si, não é (...) nenhum conceito constitutivo do entendimento ou da razão, mas pode ser um conceito regulativo para a faculdade de julgar reflexiva (...)” (KANT, 1968b, [\$ 65] p. 375).

Ora, o filósofo afirma que, se acredita ser preciso julgar certas coisas da natureza (seres organizados, por exemplo), bem como sua possibilidade, segundo causas finais. Tal investigação se dá ainda que apenas desejemos encontrar um fio condutor para pensar em como observar suas propriedades, sem investigar, com isso, sua origem (KANT, 1968b, [ $\$ 72]$ p. 389).

Uma questão lançada na seção "Dialética do juízo teleológico" é a seguinte: se essa noção de finalidade vale apenas subjetivamente, isto é, é uma mera máxima de nosso juízo, ou se é o caso de se adotar um princípio objetivo da natureza, segundo o qual, além do mecanismo, há outro tipo de causalidade ligado a ela, isto é, o princípio das causas finais, em relação a cujas leis as leis do mecanismo devem ser consideradas apenas causas intermediárias (KANT, 1968b, [\$ 72] p. 390).

Ora, o conceito de algo como fim natural é empiricamente condicionado, isto é, apenas é possível respeitando-se certas condições da experiência possível, mas incapaz de ser abstraído pelo entendimento da mesma. Tal conceito só é possível, todavia, de acordo com um princípio racional contido no juízo sobre o objeto. Portanto, a realidade objetiva de um fim natural não pode ser compreendida dogmaticamente, ou seja, não pode ser tratada pela faculdade de julgar determinante (bestimmende Urtheilskraft) (KANT, 1968b, [ 74$]$ p. 396).

Portanto, ele [o conceito de fim natural] não pode ser tratado dogmaticamente pela faculdade de julgar determinante: isto é, não só não se pode decidir se as coisas da natureza consideradas fins naturais exigem, para sua geração, uma causalidade de um tipo bem peculiar (aquela segundo intenções), ou não, mas também não se pode sequer se perguntar sobre isso, pois o conceito de fim natural não é demonstrável pela razão, no que tange à sua realidade objetiva (isto é, não é constitutivo para a faculdade de julgar determinante, mas meramente regulativo para a faculdade de julgar reflexionante) (KANT, 1968b, [\$ 74] p. 396).

Desse modo, uma coisa é afirmar que a produção de certas coisas da natureza, ou do todo da natureza, é apenas possível mediante uma causa que age segundo intenções. Isso é um procedimento dogmático, no qual se julga a partir da faculdade de julgar determinante, tratando-se de uso constitutivo das ideias, e que diz respeito à determinação de objetos. Outra coisa é dizer: "eu posso, de acordo com a constituição peculiar de minhas faculdades cognitivas, julgar em relação à possibilidade dessas coisas e de sua produção, de nenhuma outra forma senão pensando em uma causa que age intencionalmente, isto é, um ser que é produtivo de forma análoga à causalidade de uma inteligência”. Nesse caso, trata-se de um procedimento crítico, no qual se julga a partir da faculdade de julgar reflexionante, usando-se as ideias de maneira regulativa. Não se preocupa com a natureza dos próprios objetos, mas com o modo de proceder das nossas faculdades de conhecer (KANT, 1968b, [ $\$$ 75] p. 397s). 
No primeiro caso, quer-se afirmar algo sobre o objeto, e quer-se atribuir realidade objetiva a um dado conceito. No segundo, trata-se da razão se restringindo apenas ao uso regulativo das faculdades de conhecimento e respeitando as peculiaridades e limites do ser humano. (KANT, 1968b, [ $\$ 75] \mathrm{p}$. 398). Somos, de acordo com o filósofo, indispensavelmente obrigados (unentbehrlich nöthig) a atribuir o conceito de intenção à natureza para investigá-la em seus produtos organizados. Esse fio condutor (Leitfaden) é útil para a ideia de natureza como um sistema. Com ele, podem-se julgar os produtos naturais como obra intencional (KANT, 1968b, [\$ 75] p. 398).

A teleologia, para Kant, não prova a existência de um ser inteligente causador da natureza, mas apenas que, segundo a constituição de nossas faculdades cognitivas e subsequente combinação da experiência com os maiores princípios da razão, não podemos formar o conceito de um mundo com seres organizados senão pensando em uma causa suprema que opere intencionalmente. "Não podemos adotar a proposição de que há um ser inteligente originário, senão subjetivamente para o uso de nossa faculdade de julgar em sua reflexão sobre os fins da natureza, que só podem ser pensados segundo o princípio de causalidade intencional de uma causa suprema" (KANT, 1968b, [\$ 75] p. 399). Veremos, adiante, que Schelling recusa abertamente essa noção de uma intencionalidade externa como garantia de atribuição necessária de finalidade aos organismos.

Não se observam os propósitos da natureza como intencionais, mas se lhes pensam como tais (KANT, 1968b, [ $\$ 75]$ p. 399). O conceito de Naturzweck (fim natural) ou organismo diz respeito à causa da possibilidade de tal predicado, a qual só pode residir na ideia. $O$ resultado que corresponde a essa ideia (o produto) é dado na natureza, e o conceito de uma causalidade da natureza, "como um ser que age segundo fins" (als eines nach Zwecken handelnden Wesens), parece fazer da ideia de um fim natural um princípio constitutivo, cuja ideia possui, portanto, algo diferente de todas as demais ideias (KANT, 1968b, [\$ 77] p. 405).

Surge, portanto, uma peculiaridade de nosso entendimento humano em relação à faculdade de julgar em sua reflexão sobre as coisas naturais (KANT, 1968b, [ $\$ 77]$ p. 405). Certos produtos da natureza devem ser considerados por nós, em relação à sua possibilidade, como produzidos intencionalmente, como fins. Com isso, todavia, não se exige que se dê uma causa particular que tenha a representação de fim como seu fundamento determinante. Com isso, não se nega que um entendimento, diferente do - e superior ao - humano, possa encontrar o fundamento de possibilidade de tais produtos no mecanismo da natureza, isto é, em uma combinação causal para a qual o entendimento não é explicitamente aceito como causa (KANT, 1968b, [\$ 77] p. 406).

Kant sugere que se pense a relação de nosso entendimento com a faculdade de julgar, para se compreender a contingência da constituição de nosso entendimento, o que pode levar a uma peculiaridade, distinguindo-o de outros eventuais entendimentos (KANT, 1968b, [ $\$$ 77] p. 406). Tal contingência se encontra no particular (Besondern), que a faculdade de julgar deve agrupar sob o universal (das Allgemeine) dos conceitos do entendimento. $O$ universal de nosso entendimento humano não determina o particular, e é contingente a forma como coisas que concordam em um elemento comum chegam a nossa percepção. "Nosso entendimento é uma faculdade de conceitos, isto é, um entendimento discursivo" (unser Verstand ist ein Vermögen der Begriffe, d. i., ein discursiver Verstand), para o qual deve ser contingente de que tipo e quão diferente o particular pode ser dado a ele na natureza (KANT, 1968b, [\$ 77] p. 406). 
Pode-se pensar, nesse contexto, em um entendimento intuitivo (intuitiver Verstand) negativamente, no sentido de um entendimento não-discursivo, que não procede do universal ao particular. Esse entendimento não precisaria fazer com que características naturais correspondessem a nossa faculdade de conceitos (KANT, 1968b, [\$ 77] p. 406).

Kant salienta uma peculiaridade do entendimento discursivo, em relação à faculdade de julgar: no conhecimento por meio do entendimento discursivo, o particular não é determinado pelo universal, e não pode ser derivado dele. Ao mesmo tempo, o particular no múltiplo da natureza deve estar de acordo com o universal (mediante leis e conceitos) para que possa ser subsumido, e esse acordo é contingente (KANT, 1968b, [\$ 77] p. 406s) .

Kant declara, novamente, a ideia de "um outro entendimento" (einen andern Verstand), para que possamos conceber um acordo entre as coisas naturais em nosso entendimento. Segundo nosso entendimento finito, discursivo, não se pode afirmar que o todo contenha o fundamento de conexão das partes, o que seria uma contradição no conhecimento discursivo, mas apenas se pode afirmar que a representação de um todo em um entendimento não-discursivo pode conter o fundamento de possibilidade dessa forma e da conexão das partes (KANT, 1968b, [\$ 77] p. 407s).

Dessa maneira, ao julgar a natureza, mecanismo e teleologia são procedimentos de explicação que podem coexistir, sem que um contradiga o outro (KANT, 1968b, [\$ 77] p. 409). Percebemos que, para o filósofo de Königsberg, ao julgarmos um todo material, julgamos que as partes precedem o todo, mas isso não basta, pois o mecanismo não pode descrever ou explicar o que é particular aos organismos, fazendose necessário o recurso à teleologia (ZUCKERT, 2007, p. 160). Confrontemos, agora, o projeto de Kant com sua assimilação criativa por parte de Schelling.

\section{SCHELLING: MECANISMO E TELEOLOGIA SEM “NATUREZA COMO ARTE”.}

Schelling buscou, para a composição das Ideias, um conhecimento sólido e detalhado da literatura relevante e do estado das discussões das ciências naturais de então. O filósofo pós-kantiano defende uma concepção dinâmica de ciência natural (DURNER, 1994, p. 16-20) e sua proposta da filosofia da natureza envolve uma reaproximação do homem com o mundo natural que o envolve, direcionandose contra o estranhamento e o distanciamento em face da natureza que a ciência moderna promove. Buscava-se assim uma concepção total de ciência, em reação às tentativas de uma maior matematização das ciências. Tal projeto não correspondia a uma mera recusa da ciência moderna, mas buscava ser um alargamento da reflexão sobre a natureza, no qual se pretendia reunir exterior e interior, sensível e inteligível, inconsciente e consciência, buscando-se, ainda, pensar a finalidade para além das aparências e dos mecanismos (BICCA, 1989, p. 83). Filosofia da natureza e ciência natural se complementam, esta buscando compreender a natureza como objeto, como produto, aquela tentando apreender a natureza como sujeito, como produtividade - lembrando que mesmo a natureza como objeto, ou produto, é formada de produtos aparentes (Scheinprodukte), que carregam em si o dinamismo da produtividade que lhes engendra (SCHELLING, 2004, p. 41; VIEIRA, 2007, p. 30).

Schelling não é um kantiano que quer perseverar nos achados de Kant, mas sim reflete sobre a natureza a partir da filosofia crítica deste (JACOBS, 2004, p. 75) e do pensamento de outros filósofos e cientistas. Na Introdução às Ideias, o filósofo aborda o problema de um conceito reflexivo de natureza e da 
fundamentação de uma filosofia da natureza, de modo que a natureza, em sua totalidade, não será apenas pensada como uma sucessão determinada de representações de fenômenos externos, mas concebida como um processo contínuo de auto-organização que se funda na identidade definitiva entre natureza e espírito (DURNER, 1994, p. 17).

Segundo Vieira, há importantes pontos críticos no confronto entre Schelling e as filosofias transcendentais de Kant e de Fichte, dentre os quais a crítica à posição de Fichte, segundo o qual a natureza é um não-eu que resulta numa doutrina própria em favor de uma compreensão da natureza como condição para o surgimento do próprio eu (VIEIRA, 2007, p. 24). Notemos, todavia, que o filósofo de Leonberg talvez não faça justiça à posição de Fichte, servindo-se de uma crítica equivocada ou mesmo com o intuito, talvez, de fortalecer sua própria posição. Além disso, temos a proposta de uma concepção de finalidade diferente da concepção kantiana apresentada na Terceira Crítica: o filósofo de Königsberg trata do conceito de finalidade meramente como um conceito regulador, que orienta a subjetividade. Tal uso não nos permite conceber a natureza como algo que possui, em si, uma finalidade imanente (VIEIRA, 2007, p. 24). Schelling tinha um impulso de superar as posições de Kant, reagindo criticamente a problemas legados pelo mesmo, e buscando sempre soluções diferentes para eles (FRANK, 1995, p. 25).

A Introdução da obra se ocupa não da exposição de um sistema de filosofia da natureza - o que, aliás, só ocorre a partir de 1799, com textos como o Primeiro projeto de um sistema de filosofia da natureza e Bruno - mas de cumprir um intento programático. Schelling defende que a indeterminação de conceitos da física só poderia ser corrigida por um ponto de vista propriamente filosófico, sendo que a filosofia da natureza não consiste em mera "aplicação" da filosofia teórica à doutrina da natureza, de modo que não se trata de emprego de princípios abstratos ao que a ciência empírica já investigou; de modo que a filosofia da natureza não é uma teia de conceitos lançada sobre a natureza, mas um acompanhamento do ritmo próprio à natureza e a adesão a sua lógica imanente (VIEIRA, 2007, p. 31). A relação entre ciência natural e filosofia da natureza é ilustrada pelo filósofo também da seguinte maneira: a química, a matemática e a física ensinam a ler a natureza e seus elementos, mas é a filosofia que ensina a interpretar o que se leu (SCHELLING, 1994, p. 62-64).

Segundo o autor, "para que se possa filosofar, deve-se ser capaz de fazer a pergunta com a qual a filosofia começa: a pergunta pela possibilidade da natureza (de um mundo fora de nós) e, com ela, pela experiência" (SCHELLING, 1994, p. 75). O simples fato de se poder colocar a questão acerca da origem das coisas já prova que sou independente das coisas externas. Quem lança essa questão se recusa a explicar suas próprias representações pela ação de coisas exteriores sobre os órgãos de sensação. Ao se colocar essa questão, eu rompo com o mecanismo (Mechanismus), já estou em outro plano do pensar e do representar.

Nos textos publicados no jornal de Niethammer entre 1796-98, que passariam a se agrupar sob o nome de Allgemeine Übersicht der neuesten philosophischen Literatur, já se nota um progressivo distanciamento de Fichte e que o filósofo substitui o termo eu por espírito (Geist) (BICCA, 1989, p. 81-82). A unidade entre natureza e espírito é tema importante tanto nesse texto quanto nas Ideias, e é nessa mesma direção que Schelling afirma: "O primeiro que considerou o espírito e a matéria como um só, pensamento e extensão como modificações do mesmo princípio, foi Spinoza” (SCHELLING, 1994, p. 76). Schelling elogia, em Spinoza, a defesa de um ponto de vista monista. Mas não se detém no mero elogio: 
dois mundos em nós - o ideal e o real -, ele sobrevoou a si mesmo; ao invés de explicar, a partir de nossa natureza, como finito e infinito se unem originariamente em nós e resultam reciprocamente um do outro, perdeu-se imediatamente na ideia de um infinito fora de nós (...) (SCHELLING, 1994, p. 90).

O sistema de Spinoza, para ser compreendido, deve ser absorvido em nós mesmos, a substância infinita (unendlichen Substanz) deve ser substituída para se saber que infinito e finito "não se encontram fora de nós, mas em nós" (nicht ausser uns, sondern in uns). Não posso compreender um absoluto fora de mim, mas posso compreender que não possa haver nada infinito sem que, simultaneamente, haja algo infinito em mim (SCHELLING, 1994, p. 90). A unidade entre natureza e espírito não deve ser pensada fora de nós, mas em nós, e consiste em uma gradação na qual a subjetividade, o espírito, gradativamente se torna mais consciente de si mesmo, culminando em uma espécie que é o ser humano, no qual se é consciente tanto da atividade natural (por exemplo, um ato movido por um instinto) quanto da espiritual (como a reflexão).

O dogmático pressupõe que tudo existe originariamente fora de nós, e deve explicar o que se encontra fora de nós também devido a causas externas. Consegue-o servindo-se da conexão entre causa e efeito, embora nunca consiga explicar essa própria conexão. Todavia, ao tentar se elevar acima do fenômeno particular, a filosofia de Spinoza chega ao fim: "os limites do mecanismo são, também, os limites de seu sistema” (SCHELLING, 1994, p. 93). Nessa crítica ao realismo dogmático, o filósofo de Leonberg enfatiza que o seu limite, ou seja, não transcender as relações de causa e efeito, é o que a deixa impotente para lidar com as formas orgânicas (BICCA, 1989, p. 85).

"Ora, mas o mecanismo não é, nem de longe, a única coisa que constitui a natureza. Pois, assim que invadimos o domínio da natureza orgânica, toda ligação mecânica entre causa e efeito cessa para nós” (SCHELLING, 1994, p. 93). Aqui, o pensador pós-kantiano já começa a se mostrar adepto de algumas teses da "Crítica da faculdade de julgar teleológica": o organismo é um limite para o mecanicismo, entendido esse como base do método investigativo. Por conseguinte, talvez tenhamos de considerar Schelling mais radical na ruptura com o mecanismo do que Kant, que fala não de ruptura, mas de compatibilidade entre mecanismo e teleologia.

Cada produto orgânico ${ }^{6}$ subsiste por si mesmo, e sua existência (Daseyn) não depende de nenhuma outra. A organização se produz a si mesma. O organismo se produz, cada planta é produto de um indivíduo de sua espécie (ihrer Art). Cada organismo isolado produz, ao infinito, apenas sua própria espécie, regressando infinitamente a si mesmo. Não é causa, nem efeito de algo exterior a si. Cada produto orgânico possui, em si mesmo, o fundamento de sua existência, por ser causa e efeito de si mesmo (SCHELLING, 1994, p. 93s).

Nenhuma parte isolada surgiria, senão nesse todo orgânico, e este só subsiste na ação recíproca de suas partes. Nos demais objetos inorgânicos, as partes são arbitrárias (wilkürlich), e só existem na medida em que as dividimos. Já nos seres orgânicos, as partes são reais, elas existem sem minha cooperação, havendo relação objetiva entre partes e todo, e é isso justamente que o filósofo chama conceito. Há uma interessante recusa, da parte do autor, da ideia kantiana de natureza como arte (Natur als Kunst): "(...) Cada organização tem por base um conceito, pois onde há uma relação necessária entre todo e partes, entre partes e todo, há conceito. Mas esse conceito reside nela mesma, não pode ser separado dela, ela se organiza a si mesma, não é algo como uma obra de arte, cujo conceito está dado fora de si, no entendimento do 
artista" (SCHELLING, 1994, p. 94, grifos do autor).

O filósofo de Leonberg não aceita a ideia de natureza como arte, ou seja, da hipótese de que alguma forma externa de intencionalidade introduz a finalidade na natureza, tal como um artesão concebe, intencionalmente, sua arte, de modo que a natureza seria análoga a uma obra de arte. Schelling recusa essa via, tanto quando tem a pretensão de determinar objetivamente algo sobre os organismos, quanto é utilizada como instrumento de reflexão sobre os mesmos, tal como em Kant. Depreende-se, dessa argumentação e das páginas seguintes, que o pensador recusa o teísmo implícito na noção kantiana de teleologia.

O que ele herda da teleologia kantiana, basicamente, é a necessidade de se pensar além do mecanicismo; no caso de seres organizados, como a autocausalidade do organismo é relevante nesse pensamento, ela implica a recusa de se pensar a finalidade como algo que independe da consciência humana. Todavia, Schelling não irá conferir tamanho poder à subjetividade transcendental, tal como o fizera Kant, que reduzia a finalidade na natureza a uma máxima subjetiva; o filósofo de Leonberg partirá de pressupostos distintos, a saber, a identidade originária entre natureza e espírito, identidade esta que não se encontrava no pensamento kantiano. O próprio Kant concebera a importância de tentar reatar o que estava separado de forma notável em suas duas primeiras Críticas: natureza e liberdade - o que, em linguagem schellinguiana, pode ser compreendido como natureza e espírito.

O filósofo pós-kantiano acrescenta, ainda, sobre o conceito de organismo: "Não só sua forma, mas sua existência é conforme a fins. Não pode organizar a si mesmo, sem já estar organizado. A planta alimenta-se e subsiste através da assimilação de matérias externas, mas não pode assimilar nada, sem já estar organizada" (SCHELLING, 1994, p. 94, grifo do autor). O organismo é uma unidade do conceito. Suas partes só são possíveis por intermédio do todo: o todo, por sua vez, só é possível por causa da ação recíproca das partes (e não da mera justaposição delas) (SCHELLING, 1994, p. 95).

O filósofo retoma a crítica à ideia de artesão: a ideia de um entendimento superior, divino, que projetou suas criações no plano ideal, e produziu a natureza segundo esse ideal, apresenta o seguinte problema: a realização só pode configurar a matéria, dar forma a ela. O que se produz não é, ele mesmo, originariamente e em si mesmo finalizado, mas só o é contingentemente (SCHELLING, 1994, p. 97). "Não que as coisas da natureza em geral sejam conforme a fins tal como cada obra de arte também oé, mas que essa finalidade é algo que não lhes pode ser comunicada de fora, que essas coisas são algo originariamente conforme a fins por meio delas mesmas: é o que queremos saber explicar" (SCHELLING, 1994, p. 97, grifo nosso).

Kant afirmava que a natureza "não é tomada por nós como um ser inteligente" (KANT, 1968b, [ $\$$ 61] p. 359). Já Schelling não pensa a natureza como algo desprovido de espírito, uma vez que, para ele, ela é, essencialmente, um ser inteligível e mesmo inteligente (cf. FRANK, 1995, p. 81), ainda que essa inteligência ainda não seja consciente de si mesma nos organismos não-humanos. Por essa razão, deve-se recorrer, segundo Schelling, a outra harmonia preestabelecida (aquela que Leibniz, que pensou um espírito inerente aos seres organizados, "realmente quis dizer", e não a popularizada vulgarmente), admitindo nas coisas fora de nós um espírito análogo ao nosso, no qual se unem o real e o ideal, conceito e realidade, de forma inseparável (SCHELLING, 1994, p. 98s).

A filosofia que Schelling propõe deve admitir que há, na natureza, uma sucessão de estágios da vida (eine 
Stufenfolge), existindo vida na matéria simples organizada, ainda que se trate de um tipo mais limitado de vida. Segundo o autor, essa ideia antiga permaneceu presente na filosofia até a sua própria época, sob as mais variadas formas - Platão falava da totalidade do mundo penetrada por um princípio vital, a alma do mundo (Weltseele); o Leibniz tardio conferia a cada planta uma alma.

Essa filosofia, portanto, deve admitir que há uma sucessão de estágios de vida na natureza. Também há vida na simples matéria organizada, só que uma vida de um tipo mais restrito. Essa ideia é tão antiga - e manteve-se, até os dias de hoje, de formas tão distintas (já nos tempos mais antigos, deixava-se a totalidade do mundo ser penetrada por um princípio vital, chamado alma do mundo, e a época tardia de Leibniz conferiu a cada planta sua alma) -, que se pode muito bem supor, antecipadamente, que deveria haver um fundamento qualquer dessa crença natural no próprio espírito humano (SCHELLING, 1994, p. 99, grifo do autor).

Essa menção a Leibniz e, implicitamente, a Platão (que Schelling estudara desde os anos de seminário em Tübingen) e ao neoplatonismo, traz à tona uma característica do pensamento schellinguiano desse período: ele reabilita um antigo tópos da tradição filosófica, principalmente em suas obras sobre a filosofia da natureza, que é a ideia do homem como microcosmo (cf. PUENTE, 1997, p. 23). De acordo com tal compreensão, o organismo é semelhante a um microcosmo, resgatando uma visão humanista de mundo, forma de pensamento na qual o ser humano adquire papel bem importante, o que se reflete em seu mencionado papel como "ponto de encontro" entre natureza e espírito.

A proposta de Schelling sobre finalidade na natureza seria considerada por Kant como um hilozoísmo, por aceitar a existência de uma alma do mundo ${ }^{7}$. Dessa maneira, podemos indagar se a filosofia da natureza de Schelling não seria um retorno à metafísica de Platão ou à de Leibniz e de Spinoza? Na verdade, defende Jacobs, não: seria uma continuação possível do projeto crítico kantiano. Com sua crítica a Kant, Schelling se mostra mais como aluno de Kant, e não como kantiano (JACOBS, 2004, p. 78s). Podemos acrescentar que se trata de uma continuação do projeto kantiano, mas que resgata e enfatiza a visão dinâmica de natureza presente em filósofos antigos e em Leibniz.

Desse modo, seria um equívoco declarar a filosofia da natureza como regresso a uma metafísica précrítica, como volta ao realismo ou mesmo ao materialismo. Uma tese fundamentalmente kantiana, a da imanência da consciência, é preservada por Schelling (cf. JACOBS, 2004, p. 79). As próprias críticas de Schelling dirigidas a Spinoza já mostravam que seu próprio empreendimento filosófico levava em conta a revolução copernicana - ainda que não se ajoelhe totalmente a ela: a unidade entre natureza e espírito só é possível em um sujeito. Ou ainda: a filosofia da natureza reconhece a importância da subjetividade transcendental, mas quer reelaborar uma concepção dinâmica de natureza, em contraponto ao que o filósofo via como efeitos danosos de uma filosofia da subjetividade como a de Fichte ou mesmo a de Kant.

Não é preciso ficar preso a Kant, para se ler o idealismo alemão, pois isso seria desrespeitar o impulso criativo de cada filósofo. Todavia, não deixa de ser oportuno observar que Schelling provavelmente não estaria, para o próprio Kant, no rol dos filósofos críticos. Compete lembrar ainda, não obstante, que Schelling não se pretende um kantiano em sentido estrito, mas quer aprender da filosofia crítica. Sua filosofia, sem dúvida, é devedora das investigações do pensador de Königsberg e, além disso, a finalidade só é pensável no organismo porque, para Schelling, ele já apresenta em si mesmo uma forma de espírito, 
ainda que limitado, se comparado à subjetividade humana.

A natureza se revela em múltiplas formas, em desenvolvimentos sucessivos, em progressiva aproximação à liberdade (SCHELLING, 1994, p. 100). Contudo, apenas movimentos livres não definem a vida, para Schelling, pois o movimento livre pode ser produzido por estímulos exteriores, sendo o organismo um ser no qual natureza e liberdade se unem (SCHELLING, 1994, p. 101).

As capacidades dos órgãos constitutivos do indivíduo orgânico como tais não são suficientes para explicar a vida: se de um lado, a conexão de fibras, nervos, tecidos etc., poderia ser explicada com base em algo exterior, de outro, a concordância de todos os movimentos dos órgãos constitutivos de uma unidade individual surge, para Schelling, como o fundamento de explicação da produção da própria vida. Ora, essa concordância não se explica apenas com base na matéria: deve haver um princípio mais elevado, capaz de ordenar e de concentrar um todo a partir de uma multiplicidade de movimentos, os quais concordam entre si e produzem um todo. Haveria, nesse ponto, uma ligação absoluta entre natureza e liberdade num único e mesmo ser: o organismo é produto da natureza, mas há um espírito ordenador e centralizador em tal produto. Os produtos são unidos, agem simultânea e reciprocamente (SCHELLING, 1994, p. 100s).

(...) há um princípio superior que já não podemos mais explicar com base na própria matéria: um princípio que ordena e condensa todos os movimentos singulares e que, então, cria e produz um todo a partir de uma multiplicidade de movimentos que concordam entre si, produzem-se e se reproduzem reciprocamente. Portanto, encontramo-nos mais uma vez com aquela unificação absoluta entre natureza e liberdade em um e no mesmo ser. A organização vivente deve ser um produto da natureza, mas nesse produto da natureza, deve dominar um espírito ordenador e centralizado, esses dois princípios não devem estar separados na organização vivente, mas sim intimamente unidos (...) (SCHELLING, 1994, pp. 100-101).

\section{CONCLUSÃO.}

Onde reside o vínculo secreto que liga nosso espírito à natureza? Explicar essa finalidade presente no organismo recorrendo a um entendimento divino ou a um artesão, para o filósofo de Leonberg, não é filosofar, mas sim fazer considerações piedosas. De acordo com Schelling, não se quer saber como surge a matéria fora de nós, mas sim como aparece em nós a ideia de uma natureza. Como e por que essa ideia subjaz a tudo o que pensamos sobre a natureza, é o que se quer saber: "A natureza deve ser o espírito visível, o espírito, a natureza invisível. Aqui, portanto, na identidade absoluta do espírito em nós e da natureza fora de nós, deve se resolver o problema de como é possível uma natureza fora de nós" (SCHELLING, 1994, p. 107, grifo do autor).

Antes de encerrar, vejamos uma comparação feita por Bicca sobre a noção de organismo para os dois filósofos abordados: o que, em Kant, é conceito limite, isto é, designativo de algo que não pode ser conhecido, é, em Schelling, a base do projeto de uma filosofia da natureza, ou física especulativa. Para a filosofia schellinguiana, o mundo como um todo é considerado um organismo, algo conforme a fins, sem uma finalidade que lhe transcenda, isto é, que lhe seja exterior.

Assim, enquanto para Kant o organismo - entendido já como teleologia ou finalidade imanente - constitui um limite, para Schelling ele é um ponto de partida para se pensar inúmeras questões. A pergunta sobre a 
maneira de se possuir algum saber sobre os existentes orgânicos tem como resposta o não considerá-los objetos, algo oposto ao sujeito humano conhecedor, mas como algo que surge, resulta de um processo produtivo e nele continua inserido. Dentro da filosofia especulativa da natureza, um existente não é tomado como coisa acabada ou algo definitivo, tal como "se apresenta" ou "se dá", e sim como sistema das funções que se refaz, se reconstitui frequentemente (BICCA, 1989, p. 85, grifo do autor).

É digno de nota - e inovador, a nosso ver - o esforço schellinguiano de conceber um monismo a partir do sujeito, e não a partir de Deus. O filósofo herda de Kant a noção de natureza como sistema (SCHELLING, 1994, p. 106), mas não quer pensar a natureza como arte, e sim como natura naturans, como produtividade. Talvez a recusa a se pensar a natureza como arte seja um esforço, da parte do filósofo, de evitar atribuir passividade à natureza, não a vendo como mera obra projetada e moldada por um artesão, mas sim como uma semente que se espalha pelos campos e gera muitos frutos, como algo que gera e transforma a si mesmo.

\section{NOTAS}

1. Mecanismo, na terceira Crítica, pode significar explicação do todo apenas em termos de interação causal de suas partes componentes. É distinto da técnica da natureza, ou seja, da explicação teleológica, ainda que não se oponha a ela. Também abrange qualquer modo de causalidade que não opere segundo fins. Liga-se ao entendimento, portanto, a procedimentos discursivos. Cf. ALLISON, 2003, p. 221.

2. Os filósofos que exerceram influência na elaboração da filosofia da natureza de Schelling são vários: além de Kant, temos Platão, Plotino, Spinoza, Leibniz, Fichte, Jacobi e os pietistas suábios (Friedrich Oetinger e Michael Hahn, principalmente). Cf. DURNER, 1994, p. 34-36.

3. (DURNER, 1994, p. 33-34). Também são dignos de nota os Princípios metafísicos da ciência natural (1786/7) de Kant. Essa obra influenciou a noção schellinguiana de construção dinâmica da matéria. Schelling combina suas reflexões com a tese fundamental de Kant, segundo a qual a matéria deve ser pensada necessariamente como produto de forças originárias e contrapostas. Jacobs acrescenta, ainda, que o capítulo das antinomias na "Dialética Transcendental" da Crítica da razão pura (onde há a questão acerca do incondicionado) é influente no projeto de Schelling, mas raramente discutido. Cf. JACOBS, 2004, p.70.

4. Todas as traduções dos textos de Kant e de Schelling são da responsabilidade do autor do presente artigo.

5. Esse "conceito" permite-nos apenas conceber essa unificação, mas não explicar como ela se dá. Tal fundamento seria acessível apenas a um intelecto intuitivo. Esse seria o uso positivo do intelecto intuitivo: autorizar o pensamento de unificação entre mecanicismo e teleologia. Cf. ALLISON, 2003, p. 232.

6. Schelling usará, nesse texto, o termo "Organisation" (organização) com maior frequência do que "Organismus" para se referir ao produto orgânico.

7. A crítica de Kant ao hilozoísmo, ou realismo físico da finalidade, está em KANT, 1968b, p. 392-395.

\section{REFERÊNCIAS}

ALLISON, H. 2003. "Kant's Antinomy of Teleological Judgment". In: GUYER, P. (ed.). Kant's Critique of the Power of Judgment: Critical Essays. New York: Rowman \& Littlefield.

BICCA, L. 1989. "Do eu absoluto à filosofia da natureza: a trajetória da primeira filosofia de Schelling (1974-1804)”, Síntese Nova Fase, Belo Horizonte, nº 45 (1989), p. 71-88.

DURNER, M. 1994. “Editorischer Bericht”. In: SCHELLING, F. W. J. Friedrich Wilhelm Joseph Schelling 
Historisch-Kritische Ausgabe. Reihe I: Werke 5. Herausgegeben von Manfred Durner. Unter Mitwirkung von Walter Schieche. Stuttgart/Bad-Cannstatt: Frommann-Holzboog.

FRANK, M. 1995. Eine Einführung in Schellings Philosophie. 2 Aufl. Frankfurt am Main: Suhrkamp.

JACOBS, W. 2004. Schelling lesen. Stuttgart/Bad Cannstatt: Frommann-Holzboog.

KANT, I. 1968a. Kritik der reinen Vernunft. In: KANT, I. Kants Werke. Akademie-Textausgabe. Band II. Berlin: Walter de Gruyter.

. 1968b. Kritik der Urtheilskraft. In: KANT, I. Kants Werke. Akademie-Textausgabe. Band V. Berlin: Walter de Gruyter.

SCHELLING, F. W. J. 2001. Briefweschel 1786-1799. In: SCHELLING, F. W. J. Friedrich Wilhelm Joseph Schelling Historisch-kritische Ausgabe. Reihe III: Briefe 1. Stuttgart/Bad Cannstatt: Frommann-Holzboog.

.2004. Einleitung zu seinem Entwurf eines Systems der Naturphilosophie. In: SCHELLING, F. W. J. Friedrich Wilhelm Joseph Schelling Historisch-kritische Ausgabe. Reihe I: Werke 8. Manfred Durner; Wilhelm Jacobs (Hrsgs.). Stuttgart/Bad Cannstatt: Frommann-Holzboog, p. 1-86.

. 1994. Ideen zu einer Philosophie der Natur. In: SCHELLING, F. W. J. Friedrich Wilhelm Joseph Schelling Historisch-kritische Ausgabe. Reihe I: Werke 5. Herausgegeben von Manfred Durner. Unter Mitwirkung von Walter Schieche. Stuttgart/Bad Cannstatt: Frommann-Holzboog.

. 1980. Vom Ich als Prinzip der Philosophie oder über das Unbedingte im menschlichen Wissen. In: SCHELLING, F. W. J. Friedrich Wilhelm Joseph Schelling Historisch-kritische Ausgabe. Reihe I: Werke 2. Stuttgart/Bad Cannstatt: Frommann-Holzboog.

VIEIRA, L. A. 2007. Schelling. Rio de Janeiro: Jorge Zahar.

PUENTE, F. R. 1997. As concepções antropológicas de Schelling. São Paulo: Loyola.

ZUCKERT, R. 2007. Kant on Beauty and Biology. Cambridge: Cambridge University Press. 